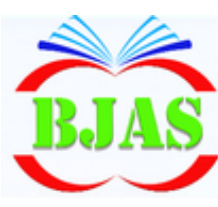

Available online at http://bajas.edu.iq

https://doi.org/10.37077/25200860.2021.34.sp1.1

College of Agriculture, University of Basrah

ISSN $1814-5868$

Basrah J. Agric. Sci., 34(Special Issue 1): 1-10, 2021
Basrah Journal

of Agricultural

Sciences

E-ISSN: 2520-0860

\title{
Relationship of Oil Palm Crown Features Extracted Using Terrestrial Laser Scanning for Basal Stem Rot Disease Classification
}

\author{
Nur A. Husin', Siti Khairunniza Bejo ${ }^{1,2,3}$ *, Ahmad F. Abdullah', Muhamad S.M. \\ Kassim $^{1,3}$ \& Desa Ahmad ${ }^{1,2}$ \\ ${ }^{1}$ Department of Biological and Agricultural Engineering, Faculty of Engineering, \\ ${ }^{2}$ Smart Farming Technology Research Centre, \\ ${ }^{3}$ Institute of Plantation Studies, Universiti Putra Malaysia, 43400 UPM Serdang, Selangor, \\ Malaysia. \\ *Corresponding author E-mail: skbejo@upm.edu.my
}

Received 19 September 2019; Accepted 18 February 2021; Available online 19 August 2021

\begin{abstract}
The oil palm is the largest plantation industry in Malaysia. It has been one of the major contributors to the country's economy and the main pillar of the commodity sectors. For over 40 years, the oil palm industry has faced a lethal and incurable disease, Basal Stem Rot (BSR), which is caused by a type of bracket fungus, Ganoderma boninense. The oil palm physical symptoms infected by BSR disease are appearance of many unopened spears, flattening of crown and smaller crown size. Terrestrial Laser Scanning (TLS, also known as ground-based LiDAR) can be used to provide accurate and precise information on tree morphology with high resolution. This study proposed an image processing technique using the ground input data taken from a TLS. Five parameters were used in the study are number of laser hits in strata $200 \mathrm{~cm}$ and $850 \mathrm{~cm}$ from the top, namely as C200 and C850, respectively, crown area, frond number and frond angle. The objectives of this study are to analyse the relationship between the parameters and to study the relationship of the parameters with the levels of BSR disease. Results have shown that all parameters were significant in all levels of healthiness with p-values less than 5\%. Frond number and frond angle showed the highest correlation value, which is equal to -0.94 . Frond angle is increasing, while frond number and crown area are decreasing concurrently with the severity levels of BSR infection.
\end{abstract}

Keywords: LiDAR, Point cloud, Image processing, Crown strata, Oil palm, BSR.

\section{Introduction}

Oil palm is a typical crop of the rainy and humid lands, suitable to be planted in tropical climate countries and mainly grown for its industrial production of vegetable oil. Oil palm is now considered as the most important supplier of vegetable oil in the world (Verheye, 2010). Oil palm industries represent the second largest export product of Malaysia (Sulaiman et al., 2011). Malaysia is one of the largest producers and exporters of palm oil in the world representing $11 \%$ of world's oils and fats production and $27 \%$ of world's export trade of oils and fats (MPOC, 2017). Basal Stem Rot (BSR) is the most destructive disease 
of oil palm in South-East Asia, especially in Malaysia. Ganoderma boninense is the causal pathogen of BSR disease (Naher et al., 2013) with a white rot basidiomycetous fungus. The pathogen infects oil palm primarily through the roots and degrades the lignin component of wood, caused dry rotting at the stem base (Paterson, 2007). The disease progresses slowly but every infected plant usually dies. In the early stages of infection plants usually appear symptomless and the symptoms appeared only when the plant is severely infected, while plants with severe symptoms are unable to be saved.

The main visible symptoms could be discovered at the external part of infected oil palms, especially at the bottom of the trees and the leaves parts (foliar symptoms). Turner \& Gillbanks (1974) and Nisfariza et al. (2010) found that the foliage symptoms of infected oil palms are the declination and skirt-like shape of crown, unfolded spears, and not welldeveloped crown size. Fig. (1) shows some severe symptoms of BSR disease which can be seen on the infected oil palm tree. Some diseases related to the palm trees occurred around the world such as in Pakistan (AbulSoad et al., 2015), India (Kandan et al., 2010), Philippines (Turner, 1982), Thailand (Pinruan et al., 2010), African countries (Mariau et al., 1996; Kinge \& Mih, 2011), Middle East countries (Djerbi, 1998; Abdelmonem \& Rasmy, 2007), USA (Elliott \& Broschat, 2000), Caribbean regions (Abad-Franch et al., 2005) and in other countries. The detection of all the diseases is still manual (visual) by looking at the external appearances. Looking at the appearance of the symptoms, it shows that the crown and the frond features were heavily affected.

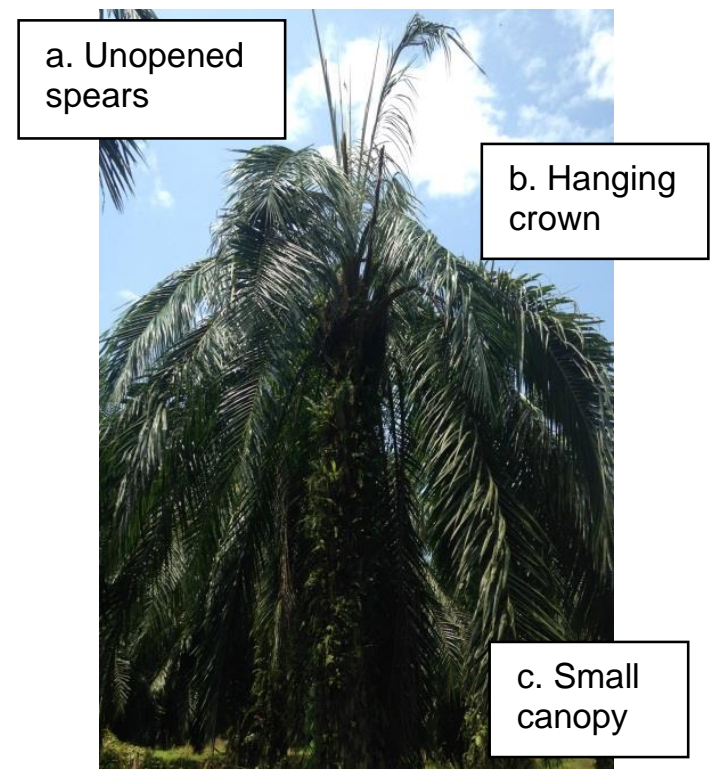

Fig. (1): Foliar symptoms of oil palm trees with severe infection of Ganoderma boninense (a c).

\section{Literature review}

There is still no specific standard visual symptoms could be used to classify the level of infection, while some researchers have contradicted assessment for the description of the trees to assess the level of infection (Lelong et al., 2010; Nisfariza et al., 2010). Generally, there are three ways to detect the BSR in oil palm trees i.e., manual method, lab-based and sensor-based. Manual method based on individual or scouts monitoring is labourintensive, prone to fatigue and low accuracy due to human dependence. Laboratory-based methods are reliable for early detection; however, they are costly, complex, time consuming and ill-suited for outdoor conditions (Naher et al., 2013). Multispectral imaging (Santoso et al., 2011, KhairunnizaBejo et al., 2015, Bejo et al., 2018) and hyperspectral imaging (Lelong et al., 2010; Nisfariza et al., 2010; Shafri et al., 2011; Izzuddin et al., 2013; Liaghat et al., 2014; Izzuddin et al., 2015; Ahmadi et al., 2017) techniques can differentiate between healthy and unhealthy oil palm trees with varying 
levels of accuracy. However, these techniques insufficiently discriminate the different levels of severity. Rapid, easy, non-destructive, noninvasive and accurate detection tool is in need since oil palm plantation is cultivated in the extensively wide area (Khairunniza-Bejo et al., 2015).

Lidar technology has been used to obtain geometrical attributes of the target and was proven to be a feasible option for modelling three dimensional (3D) features of tree crops (Colaco et al., 2017). Terrestrial Laser Scanning (TLS), also known as ground-based LiDAR (Light Detection and Ranging) is an active imaging method which is contact-free, precise, cost-effective and user-friendly contributed to its expanding use. These 3D profiling systems have some features that can provide accurate information about tree dimensions and morphology, which relates to plant development and health, such as high degree of accuracy and precision, up to $\mathrm{mm}$ (Campos et al., 2014). Recent studies have shown the use of TLS to monitor the plant growth and physiology of plant canopy is promising (Lumme et al., 2008; Keightley \& Bawden, 2010; Tilly et al., 2014; Hoffmeister et al., 2016). Based on the literature, it can be concluded that TLS is well-adapted for intensive study of tree geometry in-situ. Yet, there exist very few TLS studies focusing on a fine level of oil palm tree architecture especially on the canopy analysis for disease detection. The first preliminary study on the use of TLS for BSR detection was performed by Khairunniza-Bejo \& Vong (2014). The results showed that there were correlations between the oil palm trunk's perimeter, Diameter at breast height (DBH) and canopy area with the BSR disease. This preliminary study supported the potential use of TLS for analysing the properties of oil palm trees to distinguish healthy and infected BSR at different levels of infection. Recently, Azuan et al. (2019) has shown that crown pixel, frond number and frond angle extracted from TLS data gave significant different in classifying BSR and non-BSR oil palm trees. Meanwhile, Husin et al. (2020) have developed classification models using selected crown strata and top-down view images for BSR detection. Hence, the previous studies did not incorporate all the significant single parameters for analysing the relationships between the parameters and the order of significant changes that can be seen on the parameters across the severity levels of BSR infection. Therefore, the objective of this research is to study the relationships between the oil palm crown features extracted using TLS method for BSR disease classification.

\section{Materials \& Methods}

\section{Terrestrial laser scanner}

In this study, physical characteristics of oil palm tree were analyzed using Faro Laser Scanner Focus 3D data (FARO Technologies, Inc., Florida, USA). FARO laser scanner uses high-speed laser technology to acquire millions of three-dimensional (3D) laser points for detailed measurement and documentation in significantly shorter time. Since the field of view of Faro Laser Scanner Focus 3D is $360^{\circ}$ $\times 305^{\circ}$, therefore, ground scanning has the capability to scan top view of the tree. Repetition of the single point measurements is up to 976,000 times per second, which results into a Point Cloud (a 3D dataset of the scanner's environment known as laser scan). The laser scan was recorded on a removable SD memory card which then can be transferred to the SCENE software (version 5.0, FARO Technologies, Inc.), which is FARO's point cloud processing software for further analysis. 
Husin et al. / Basrah J. Agric. Sci., 34(Special Issue 1): 1-10, 2021

\section{Data collection}

The study area is located at the oil palm plantation in Seberang Perak, Malaysia. The age of oil palm trees is 9 years old while the heights of the trees were range between 10 to 11 meters, where the production is at the peak. The oil palm trees are categorized into four healthiness levels: $\mathrm{T} 0$ is the tree without BSR disease, $\mathrm{T} 1$ is the mildly infected, T2 for moderately infected and T3 for severely infected BSR disease (Fig. 2). Categorization of the trees is followed by descriptions provided by Malaysian Palm Oil Board (MPOB) as shown in Table (1) (KhairunnizaBejo et al., 2017; Bejo et al., 2018). A total of 40 oil palm trees had been selected with 10 trees for each healthiness level randomly taken from several different locations in the same block to minimise the environmental variation effects.

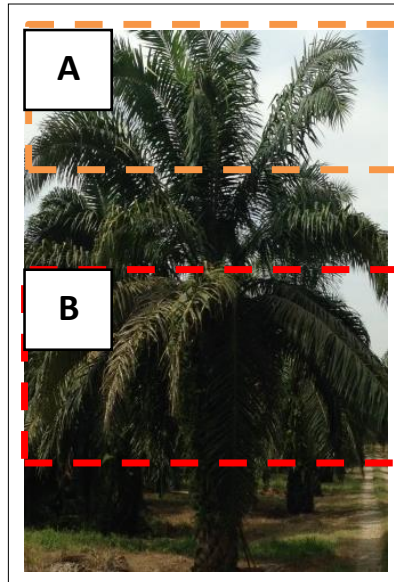

TO - healthy

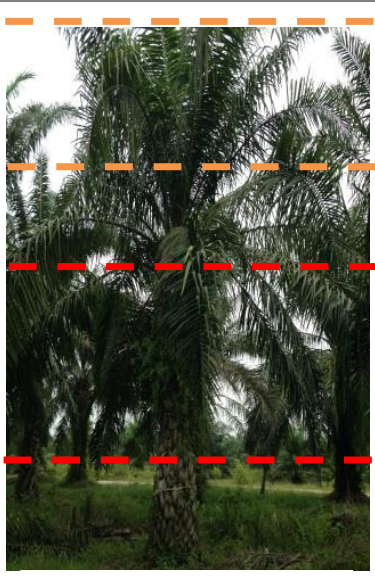

T1 - mild infection

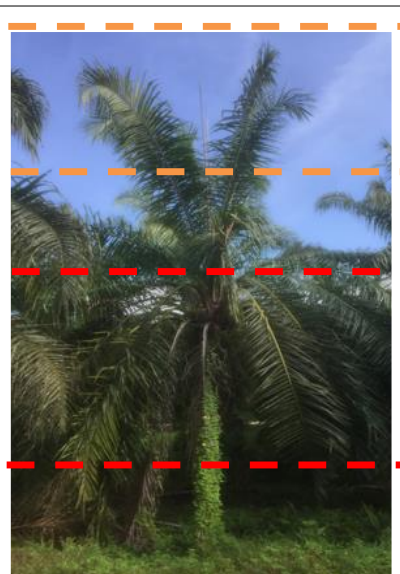

T2 - moderate infection

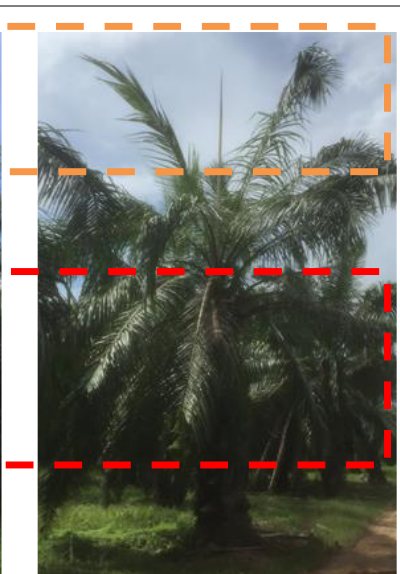

T3 - severe infection

A = Number of spears in increasing and upper crown is less dense from T0 to T3.

$\mathbf{B}=$ Crown is flattening and the size is getting smaller from T0 to T3.

Fig. (2): Pictures of oil palm tree based on the healthiness level.

Table (1): Classification and tree descriptions.

\begin{tabular}{cr}
\hline Classification & Trees observations \\
\hline T0 & Healthy palm, no foliage symptom $(0 \%)$, no fruiting body \\
\hline T1 & Mild infection, foliage symptom (1-25\%), produce fruiting body \\
\hline T2 & Moderate infection, foliage symptom (26-50\%), fruiting body \\
\hline T3 & Severe infection, foliage symptom $(>51 \%)$ and fruiting body
\end{tabular}

The data were collected on 7 to 11 of July 2017. The scanner was mounted on a surveying tripod at the height of $1 \mathrm{~m}$ and a distance of $1.5 \mathrm{~m}$ from the oil palm tree. Tripod 
was placed on firm ground and levelled it using a bubble balancer. Five to eight reference spheres were placed around the tree and each tree was scanned four times from different scan locations around the tree. Spheres were used as a reference in case a problem is found when synchronizing the scanned data.

\section{Data processing}

SCENE software (version 5.0, FARO Technologies, Inc.) was used for pre- and postprocessing of the laser scans. The scans were processed through the 'registration' step, where four TLS scans were matched for every tree and the laser point data were synced to create a cluster of point clouds and a complete $3 \mathrm{D}$ view of the tree. The image of the frond from top view was analysed using AutoCAD software (Autodesk, Inc., San Rafael, USA). 'Polyline' was used to draw the shape of the frond on the image. Next, 'Dimension' tool was selected to determine the distance between each frond (measured in angle). Meanwhile, the area of crown for each tree was determined by counting number of pixels inside the crown image. The details of the steps can be referred to the study by Azuan et al. (2019).

The density of the crown strata indicates the thickness of oil palm fronds at various heights. Different values of laser hits in crown strata were used to identify crown strata that can provide significant differences between all severity levels of infection. Stratification method was used to segment the point cloud data of oil palm trees for data reduction (Ayrey et al., 2017). Series of horizontal layers (known as strata) with equal interval and size perpendicular to the vertical direction were created. The thickness of the clipping box was set to $0.1 \mathrm{~m}$ and the space between the boxes was set to $0.5 \mathrm{~m}$ following Bienert et al. (2006) and Lovell et al. (2011) (Fig. 3). The details of the steps can be referred to the study by Husin et al. (2020).

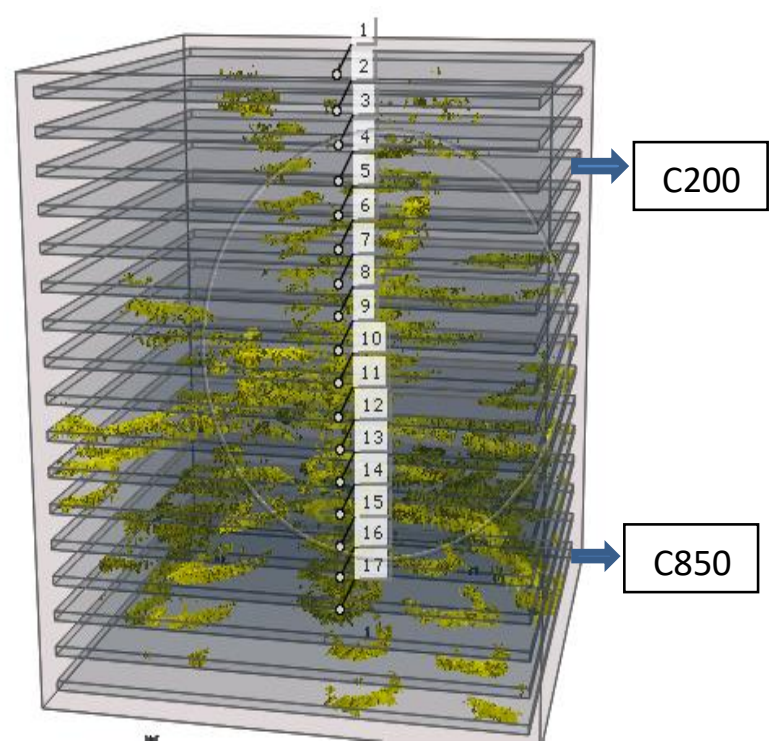

Fig. (3): Stratification method.

\section{Oil palm crown parameters}

Five parameters were used for the classification models: frond number, frond angle, crown pixel, C200 and C850. C200 is the crown stratum located $200 \mathrm{~cm}$ from the top, while C850 is the crown stratum located 850 $\mathrm{cm}$ from the top. JMP software (SAS Institute, North Carolina, USA) was used to statistically analyse the data using Kruskal-Wallis test at $5 \%$ significance level $(\alpha=0.05)$. In addition, Microsoft Excel (Microsoft, Washington, USA) was used to calculate the correlations between the parameters.

\section{Results \& Discussion}

\section{Statistical analysis}

Table (2) shows the summary of KruskalWallis test results, where all the parameters showed significant difference between the levels of healthiness at $5 \%$ significance level. Crown area, frond angle and frond number presented the lowest p-value, less than $0.01 \%$, followed by C200, with p-value of 0.0166 and 
C850, with p-value of 0.0471. The highest Chi square value was obtained by frond number, 33.428 and the lowest was obtained by C850, 8.058 .

\section{Table (2): Kruskal-Wallis test for every parameter.}

\begin{tabular}{lcc}
\hline \multicolumn{1}{c}{ Parameters } & $\begin{array}{c}\text { Chi square } \\
\text { value }\end{array}$ & p-value \\
\hline C200 & 10.248 & $0.0166^{*}$ \\
C850 & 8.058 & $0.0471^{*}$ \\
Crown area & 23.058 & $<.0001^{*}$ \\
Frond Angle & 32.666 & $<.0001^{*}$ \\
Frond Number & 33.428 & $<.0001^{*}$ \\
\hline
\end{tabular}

*significant at $5 \%$ level

\section{Relationship between the parameters}

Table (3) shows the Pearson correlation value for all the parameters namely frond number, frond angle, crown area, C200 and C850. The highest correlation was shown by frond number and frond angle, which is equal to 0.94. It depicts that the lower number of fronds, the larger the angle would be found on the tree. The second highest correlation was shown by frond number and crown area, which is equal to 0.76 . It indicates that healthy oil palm trees that have higher number of fronds associate with larger crown area, while unhealthy trees have lower number of fronds relate with smaller crown area. In addition, the correlation between crown area and frond angle, -0.74, which demonstrates that the larger the crown area, more frond number will be found in the tree, which reflects to smaller degree of inter-fronds angle.

The effects of BSR disease to the crown structures are clearly shown in fig. (4). The crown area is reducing parallel with the severity levels of disease infection, which also shown by the number of pixels, decreasing from T0 to T3. Ganoderma boninense fungus produces many enzymes that damage the internal part of the oil palm trees lead to nutrient deficiencies, stunted growth and smaller crown sizes. Furthermore, number of fronds is reducing and degree of angles between fronds is increasing concurrent with the severity levels of infection. Healthy oil palm trees show normal growth of fronds. While in infected trees, the fungus had effects on the growth of new leaves, causing more unopened spears and unfolded leaves. Besides, infected trees have fewer fronds due to the slow growth and collapsing of the fronds caused by the infection, and higher pruning to remove hanging fronds in harvesting by the plantation workers. These results relate with the outcomes in table (3), where decreasing number of fronds in infected trees, decrease the area of crown and increase the angle between the fronds.

\section{Conclusions}

Based on the results, it can be concluded that the comprehensive laser point data from terrestrial laser scanner could be used to extract physical features of oil palm trees for BSR severity classification. The extracted features namely stratified point cloud at strata $200 \mathrm{~cm}$ and $850 \mathrm{~cm}$ from the top, crown coverage area, number of fronds and interfrond angle could be used as parameters to differentiate non-infected and infected oil palm at different severity levels. High correlations were also shown between the parameters. This image processing technique using the input parameters from the ground could be explored for early detection, management and control strategies of the disease. The technique also could be used for in-situ application with support of good preprocessing and post-processing facilities.

For future works, additional oil palm tree's architecture or parameters could be explored to get a better understanding of the physical attributes of the BSR disease symptoms and 
Husin et al. / Basrah J. Agric. Sci., 34(Special Issue 1): 1-10, 2021

use it for early detection and severity detection of the disease. The current approach of using four scanning positions for a single tree at a time could be improved by scanning a group of trees using multiple scanning positions. Furthermore, LiDAR sensor could be implemented on a mobile or drone platforms to reduce the time needed for scanning and for larger area application. Meanwhile, the parameters such as frond angle and frond number could be automatically calculated using the deep learning techniques.

Table (3): Correlation between the parameters.

\begin{tabular}{lccccc}
\hline \multicolumn{1}{c}{ Parameters } & Frond number & Frond angle & Crown area & C200 & C850 \\
\hline Frond number & 1.0000 & -0.9389 & 0.7566 & -0.3696 & -0.3928 \\
Frond angle & -0.9389 & 1.0000 & -0.7421 & 0.3136 & 0.2839 \\
Crown area & 0.7566 & -0.7421 & 1.0000 & -0.2105 & -0.2605 \\
C200 & -0.3696 & 0.3136 & -0.2105 & 1.0000 & 0.3720 \\
C850 & -0.3928 & 0.2839 & -0.2605 & 0.3720 & 1.0000 \\
\hline
\end{tabular}

\begin{tabular}{|c|c|c|c|}
\hline Level & Point cloud & Crown area & Frond properties \\
\hline TO & & No. of pixels : 104896 & $\begin{array}{l}\text { No. of fronds: } 23 \\
\text { Angle of fronds: } 14.7^{\circ}\end{array}$ \\
\hline T1 & & No. of pixels: 97852 & $\begin{array}{l}\text { No. of fronds: } 17 \\
\text { Angle of fronds: } 21.5^{\circ}\end{array}$ \\
\hline $\mathrm{T2}$ & & No. of pixels : 75896 & $\begin{array}{l}\text { No. of fronds: } 14 \\
\text { Angle of fronds: } 25.3^{\circ}\end{array}$ \\
\hline
\end{tabular}


Husin et al. / Basrah J. Agric. Sci., 34(Special Issue 1): 1-10, 2021

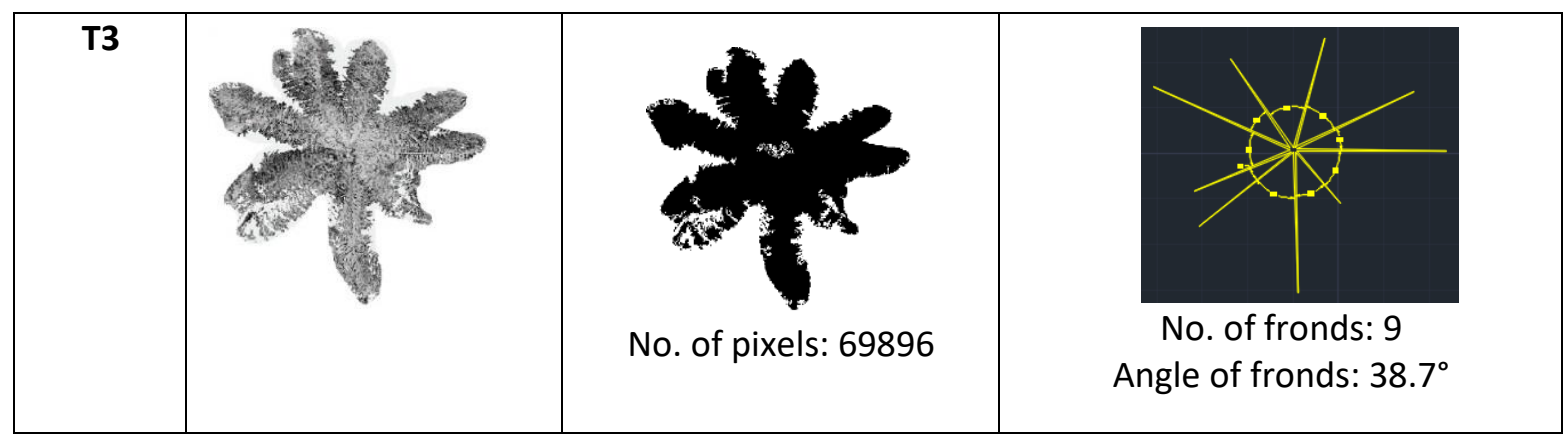

Fig. (4): Examples of crown area and frond top view images according to level of healthiness.

\section{Acknowledgements}

The authors would like to acknowledge Ministry of Higher Education (MOHE) and Universiti Putra Malaysia (UPM) for sponsoring this research under research number LRGS-NANOMITE/ 5526305.

\section{Conflicts of interest}

The authors declare that they have no conflict of interests.

\section{References:}

Abad-Franch, F., Palomeque, F. S., Aguilar, H. M., \& Miles, M. A. (2005). Field ecology of sylvatic Rhodnius populations (Heteroptera, Triatominae): Risk factors for palm tree infestation in western Ecuador. Tropical Medicine and International Health, 10, 1258-1266. https://doi.org/10.1111/j.1365-3156.2005.01511.x

Abdelmonem, A. M., \& Rasmy, M. R. (2007). Major diseases of date palm and their control. Communicationes Instituti Forestalis Bohemicae, 23, 9-23.

Abul-Soad, A. A., Mahdi, S. M., \& Markhand, G. S. (2015). Date palm status and perspective in Pakistan. In Date palm genetic resources and utilization: pp. 153-205. Springer Netherlands.

Ahmadi, P., Muharam, F. M., Ahmad, K., Mansor, S., \& Abu Seman, I. (2017). Early detection of Ganoderma basal stem rot of oil palms using artificial neural network spectral analysis. Plant Disease, 101, 1009-1016. https://doi.org/10.1094/PDIS-12-16-1699-RE

Ayrey, E., Fraver, S., Kershaw Jr., J. A., Kenefic, L. S., Hayes, D., Weiskittel, A. R., \& Roth, B. E. (2017). Layer stacking: A novel algorithm for individual forest tree segmentation from LiDAR point clouds. Canadian Journal of Remote Sensing, 43, 16-27. https://doi.org/10.1080/07038992.2017.1252907

Azuan, N. H., Khairunnniza-Bejo, S., Abdullah, A. F., Kassim, M. S. M., \& Ahmad, D. (2019). Analysis of changes in oil palm canopy architecture from basal stem rot using terrestrial laser scanner. Plant Disease, $\quad 103, \quad 3218-3225$. https://doi.org/10.1094/PDIS-10-18-1721-RE

Bejo, S., Abdol-Lajis, G., Abd-Aziz, S., Abu-Seman, I., \& Ahamed, T. (2018). Detecting Basal Stem Rot (BSR) disease at oil palm tree using thermal imaging technique. Proceedings of the 14th International Conference on Precision Agriculture, International Society of Precision Agriculture, 24 - 27 June, 2018, Montreal, Quebec, Canada: 8pp.

Bienert, A., Maas, H. G., \& Scheller, S. (2006). Analysis of the information content of terrestrial laser scanner point clouds for the automatic determination of forest inventory parameters. In Workshop on 3D Remote Sensing in Forestry, Vienna, Austria, 14, 17.

Campos I. L., Veronez, M. R., Wohnrath T. F. M., de Souza, M. K., da Silva, R. M., \& Blum Silveira, C. L. (2014). Spectral pattern classification in lidar data for rock identification in outcrops. The Scientific World Journal, 2014, 539029. https://doi.org/10.1155/2014/539029

Colaço, A. F., Trevisan, R. G., Molin, J. P., \& RosellPolo, J. R. (2017). A method to obtain orange crop geometry information using a mobile terrestrial laser scanner and 3D modeling. Remote Sensing, 9, 763. https://doi.org/10.3390/rs9080763

Djerbi, M. (1998). Diseases of the date palm: present status and future prospects. Journal of Agricultural and Marine Sciences [JAMS], 3,103-114. 


\section{Husin et al. / Basrah J. Agric. Sci., 34(Special Issue 1): 1-10, 2021}

https://doi.org/10.24200/10.24200/jams.vol26iss1p p1-12

Elliott, M. L., \& Broschat, T. K. (2000). Ganoderma Butt Rot of Palms. University of Florida, Florida, Gainesville, 2000, 5. http://vanderbiltlakes.net/PALMS/palmGanoderma ButtRotPP10000.pdf

Hoffmeister, D., Waldhoff, G., Korres, W., Curdt, C., \& Bareth, G. (2016). Crop height variability detection in a single field by multi-temporal terrestrial laser scanning. Precision agriculture, 17, 296-312. https://doi.org/10.1007/s11119-015-9420-y

Husin, N. A., Khairunniza-Bejo, S., Abdullah, A. F., Kassim, M. S., Ahmad, D. \& Azmi, A. N. (2020). Application of Ground-Based LiDAR for Analysing oil palm canopy properties on the occurrence of Basal Stem Rot (BSR) Disease. Scientific reports, 10, 1-16. https://doi.org/10.1038/s41598-02062275-6

Izzuddin, M. A., Idris, A. S., Nisfariza, N. M., \& Ezzati, B. (2015). Spectral based analysis of airborne hyperspectral remote sensing image for detection of Ganoderma disease in oil palm. In Proceedings of 2015 International Conference on Biological and Environmental Science .Phuket, Thailand. 13-20.

Izzuddin, M. A., Idris, A. S., Wahid, O., Nishfariza, M. N. \& Shafri, H. Z. M. (2013). Field spectroscopy for detection of Ganoderma disease in oil palm. MPOB Information Series, 532pp.

Kandan, A., Bhaskaran, R. \& Samiyappan, R. (2010). Ganoderma-a basal stem rot disease of coconut palm in south Asia and Asia pacific regions. Archives of Phytopathology and Plant Protection, 43, 14451449. https://doi.org/10.1080/03235400802536527

Keightley, K. E. \& Bawden, G. W. (2010). 3D volumetric modeling of grapevine biomass using Tripod LiDAR. Computers and Electronics in Agriculture, 74 ,

305-312. https://doi.org/10.1016/j.compag.2010.09.005

Khairunniza-Bejo, S., \& Vong, C. N. (2014). Detection of basal stem rot (BSR) infected oil palm tree using laser scanning data. Agriculture and Agricultural Science Procedia, 2, 156-164. https://doi:10.1016/j.aaspro.2014.11.023

Khairunniza-Bejo, S., Yusoff, Y., Yusoff, N. S. N., Seman, I. A., \& Anuar, M. I. (2015). Identification of healthy and BSR-infected oil palm trees using color indices. International Journal of Agricultural and Biosystems Engineering, 8, 786-789.

Khairunniza-Bejo, S., Jaleni, M., Husin, M. E., Khosrokhani, M., Muharam, F. M., Seman, I. A., \& Anuar, M. I. (2017). Basal Stem Rot (BSR) detection using textural analysis of Unmanned Aerial Vehicle (UAV) image. NanoMite Annual Symposium , 3, 4045 .

Kinge, T. R., \& Mih, A.M. (2011). Ganoderma ryvardense $\mathrm{sp}$. nov. associated with basal stem rot (BSR) disease of oil palm in Cameroon. Mycosphere, 2, 179-188.

Lelong, C. C., Roger, J. M., Brégand, S., Dubertret, F., Lanore, M., Sitorus, N., Raharjo, D., \& Caliman, J. P. (2010). Evaluation of oil-palm fungal disease infestation with canopy hyperspectral reflectance data. Sensors, $\quad 10, \quad 734-747$. https://doi.org/10.3390/s100100734

Liaghat, S., Ehsani, R., Mansor, S., Shafri, H. Z., Meon, S., Sankaran, S., \& Azam, S. H. (2014). Early detection of basal stem rot disease (Ganoderma) in oil palms based on hyperspectral reflectance data using pattern recognition algorithms. International Journal of Remote Sensing, 35, 3427-3439. https://doi.org/10.1080/01431161.2014.903353

Lovell, J. L., Jupp, D. L. B., Newnham, G. J., \& Culvenor, D. S. (2011). Measuring tree stem diameters using intensity profiles from groundbased scanning lidar from a fixed viewpoint. ISPRS Journal of Photogrammetry and Remote Sensing, 66, 46-55. https://doi.org/10.1016/j.isprsjprs.2010.08.006

Lumme, J., Karjalainen, M., Kaartinen, H., Kukko, A., Hyyppä, J., Hyyppä, H., Jaakola, A., \& Kleemola, J. (2008). Terrestrial laser scanning of agricultural crops. International Archives Photogrammetry Remote Sensing and Spatial Information Sciences, 37: 563-566.

Mariau, D., Dery, S. K., Sangare, A., N'Cho Yavo, P., \& Philippe, R. (1996). Coconut lethal yellowing in Ghana and planting material tolerance. Plantations Recherche Développement, 3, 105-112. http://www1.biologie.uni-hamburg.de/bonline/library/palms/vpe_coconutly $2 . \mathrm{htm}$

MPOC. (2017). Malaysian Palm Oil Industry. Malaysian palm Oil Council. Retrieved on January 2016 from MPOC Website: http://mpoc.org.my/malaysian-palm-oil-industry/ 


\section{Husin et al. / Basrah J. Agric. Sci., 34(Special Issue 1): 1-10, 2021}

Naher, L., Yusuf, U. K., Ismail, A., Tan, S. G., \& Mondal, M. M. A. (2013). Ecological status of 'Ganoderma' and basal stem rot disease of oil palms (Elaeis guineensis Jacq.). Australian Journal of Crop Science, 7, 1723-1727.

Nisfariza, M. N., Shafri, Z. H., Idris, A., Steven, M., Boyd, D., \& Mior, M. (2010). Hyperspectral sensing possibilities using continuum removal index in early detection of Ganoderma in oil palm plantation. In: World Engineering Congress 2010, Conference on Geomatics and Geographical Information Science Kuching, Malaysia. 233-239.

Paterson, R. R. M. (2007). Ganoderma disease of oil palm-A white rot perspective necessary for integrated control. Crop Protection, 26, 1369-1376. https://doi.org/10.1016/j.cropro.2006.11.009

Pinruan, U., Rungjindamai, N., Choeyklin, R., Lumyong, S., Hyde, K. D. \& Jones, E. G. (2010). Occurrence and diversity of basidiomycetous endophytes from the oil palm, Elaeis guineensis in Thailand. Fungal Diversity, 41, 71-88. https://doi.org/10.1007/s13225-010-0029-1

Santoso, H., Gunawan, T., Jatmiko, R. H., Darmosarkoro, W., \& Minasny, B. (2011). Mapping and identifying basal stem rot disease in oil palms in North Sumatra with QuickBird imagery. Precision Agriculture, $\quad 12, \quad 233-248$. https://doi.org/10.1007/s11119-010-9172-7.

Shafri, H. Z., Anuar, M. I., Seman, I. A., \& Noor, N. M. (2011). Spectral discrimination of healthy and
Ganoderma-infected oil palms from hyperspectral data. International Journal of Remote Sensing. 32, 7111-7129. https://doi.org/10.1080/01431161.2010.519003

Sulaiman, F., Abdullah, N., Gerhauser, H., \& Shariff, A. (2011). An outlook of Malaysian energy, oil palm industry and its utilization of wastes as useful resources. Biomass and Bioenergy, 35, 3775-3786. https://doi.org/10.1016/j.biombioe.2011.06.018

Tilly, N., Hoffmeister, D., Cao, Q., Huang, S., LenzWiedemann, V., Miao, Y., \& Bareth, G. (2014). Multitemporal crop surface models: accurate plant height measurement and biomass estimation with terrestrial laser scanning in paddy rice. Journal of Applied Remote Sensing, 8, 083671. https://doi.org/10.1117/1.JRS.8.083671

Turner, P. D. (1982). Limitations imposed by disease on oil palm cultivation and yield [esp. fungal diseases]. In International Conference on Oil Palms in Agriculture in the Eighties, Kuala Lumpur (Malaysia), 443-455 pp.

Turner, P. D., \& Gillbanks, R. A. (1974). Oil Palm Cultivation and Management. Incorporated Society of Planters, 672 pp.

Verheye, W. (2010). Growth and Production of Oil Palm. In Land use, Land Cover and Soil Sciences. Willy H. Verheye; UNESCO-EOLSS Publishers. Oxford, U. K. 24 pp. 